\title{
Strong Interest Demonstrated at Inaugural Meeting of Northern California Local Section
}

The Palo Alto Research Center of the Xerox Corporation was the site of a successful first gathering of California researchers interested in forming a Local Section of the MRS. The venue of the November 5th meeting was relocated to the main auditorium of Xerox PARC to accommodate the unexpected high turnout of 150 people who participated in the half-day technical program and follow-up organizational meeting. The overwhelming response confirmed the organizers' belief that many Bay Area scientists desire an appropriate forum where issues of current technical interest in materials research can be discussed.

The technical program portion of the meeting covered the topic "Silicon Wafer Materials Quality," featuring speakers John Carruthers of Intel, Marjorie Balazs of Balazs Analytical Labs, Jerry Gayer of Monsanto, Jack Williams of Siltec, and Joe Berger of VLSI Standards. Following the technical program, 1985 MRS President Elton Kaufmann described to the attendees the activities of the Society and answered questions concerning the role of Local Sections.

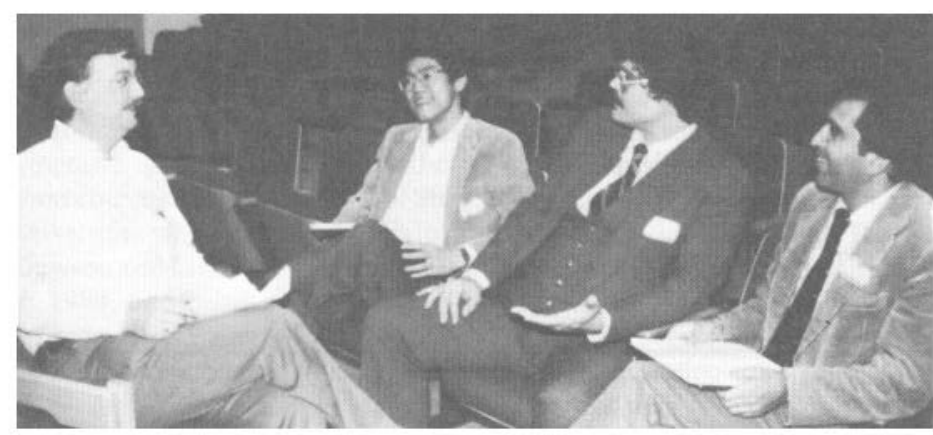

Northern California Section organizers (left to right) Michael Current, Nathan Cheung, Michael Strathman, and Devendra Sadana discuss future activities of the new MRS Section.

\section{Second Meeting in Preparation}

The next meeting of the Northern California Section is now in the planning stages, and the organizers invite suggestions for future topics and formats to enable the Section to continue to serve the needs of the local technical community. Interested persons may direct queries and comments to organizers Nathan Cheung of the University of California at Berkeley, Michael Current of Xerox PARC, Devendra Sadana of Signetics Corp., or Michael Strathman of Charles Evans \& Associates.

The four organizers bring to the Section a wealth of ideas from their individual experiences in organizing technical programs. Sadana, in particular, was one of the founders of the first MRS Local Section in North Carolina prior to his move to California.

The Northern California Local Section was officially chartered during a Monday evening ceremony preceeding the Plenary Session of the MRS Fall Meeting in Boston. See article on page 21.

\section{Why a Local Section}

Many technical societies have found that local section activities are excellent means for researchers in a particular geographic area to meet and exchange information on a frequent basis while taking less time away from their other duties. In this respect the meetings are useful supplements to the larger, less frequent annual meetings. MRS Local Sections are expected to treat topics of interest to their members in an interdisciplinary fashion similar to that found in symposia at national meetings. Information on how to form an MRS Local Section can be obtained from the MRS Membership Committee (chaired in 1985 by Rod Ewing of the University of New Mexico).

\section{Third Student Chapter Recognized on Heels of Fall Meeting}

Immediately following the Boston Meeting, Case Western Reserve University welcomed MRS President-Elect Elton Kaufmann, who officially inaugurated the university's MRS Student Chapter. The Chapter, the third such chapter for the Society, was also recognized at the Fall Meeting, but the December 3 ceremony at Case Western in Cleveland enabled student members, officers, and university officials unable to attend the meeting in Boston to participate in the historic event.

Kaufmann conducted a technical seminar on his current research and then presented the new Student Chapter's charter to Chapter President Toni Grobstein who studies metallurgy in the Department of Metallurgy and Materials Science. Among the $\mathbf{3 0}$ or more attendees at the Case Western ceremony were Chapter Vice President Michael Biddle (Department of Macromolecular Science), Secretary/Treasurer Kevin Kedder (Chemistry Department), Prof. Donald Schuely (dean of the Case Institute of Technology), and Prof. Terry E. Mitchell (Department of Metallurgy and Materials Science and the Chapter's faculty advisor).

This Chapter, as well as other MRS chapters and sections, Kaufmann noted, are unique in that the same interdisciplinary character that is reflected in the national Society is also represented in these local groups. The program committee of the Case Western Chapter further illustrates this fact. Committee members are Mark Occhionero (ceramics area of the Department of Metallurgy and Materials Science), Joe Kupanski (Electrical Engineering), Edward Makovos (Chemical Engineering), and Wayne Jennings (Department of Physics).

\section{New Chapter Benefits Announced}

As part of the inaugural ceremony in Cleveland, Kaufmann announced for the first time two new activities in the Society aimed toward serving the
Student Chapter programs. On Saturday, December 1, the MRS Council approved two new initiatives for the coming year. The first is the creation of a "speakers tour" program whereby the MRS will provide partial support to help facilitate visits to campuses by eminent materials scientists. The visits would include a seminar sponsored by the MRS Student Chapter and opportunities for students and faculty to interact with their special guest. The second initiative is the creation of a "travel grant" program to be used to assist students in attending annual meetings of the Society.

Details concerning both developments will be provided by the Education Committee, which is implementing both programs.

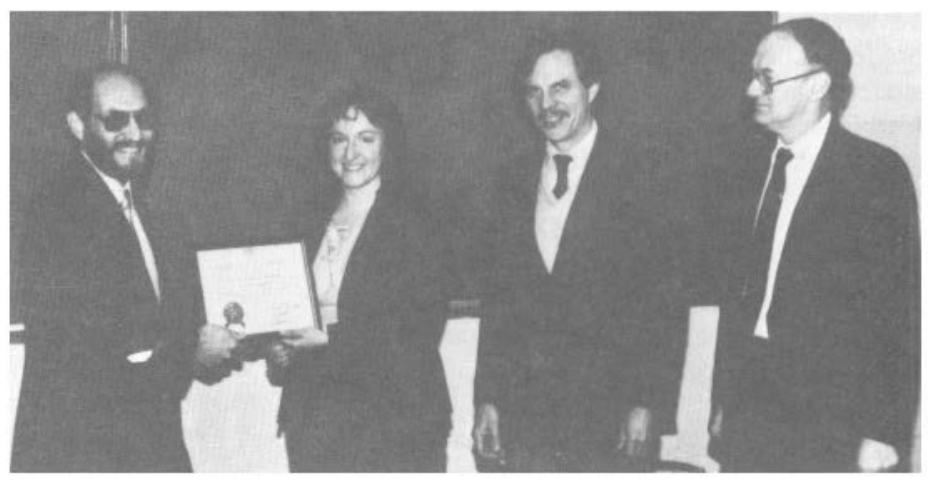

Kaufmann presents Certificate of Charter to Student Chapter President Toni Grobstein, as Prof. Terry Mitchell and Dean Donald Schuely look on. 